\title{
MUDANÇAS CULTURAIS, MUDANÇAS RELIGIOSAS Perfis e Tendências da Religiosidade em Portugal Numa Perspetiva Comparada [Eduardo Duque, 2014, Vila Nova de Famalicão, Edições Húmus]
}

\section{José Pereira Coutinho}

Númena, Porto Salvo, Portugal

Eduardo Duque, professor auxiliar na Universidade Católica Portuguesa (Braga), apresentou em 2008 a sua tese de doutoramento em sociologia na Universidade Complutense de Madrid, recebendo pela mesma o Prémio Extraordinário. O presente livro atualiza a sua tese, diferenciando-a apenas em dois aspetos. Primeiro, um dos sete objetivos específicos da tese não foi desenvolvido neste livro ("Indagar se a igreja católica continua a ser um dos grandes mobilizadores da sociedade portuguesa e consequentemente um dador de sentido"). Segundo, sendo este livro posterior à última edição do European Values Study (EVS), realizada em 2008, o autor prescindiu das outras bases de dados internacionais utilizadas na sua tese, empregando unicamente o EVS. As conclusões dos dois trabalhos, na sua amplitude, são iguais, mesmo que haja ligeiras dissemelhanças nos resultados, decorrentes da aplicação de anos e de bases de dados diferentes.

Assente na sociologia compreensiva de Weber, o autor desenvolve uma abordagem sistémica, para examinar a realidade de forma alargada. A complexidade da realidade sociocultural, assim como da realidade religiosa inclusa na mesma, é demasiada para se optar por modelos simples de análise, de causalidade linear. Esta opção também se justifica pela aspiração do autor a analisar a realidade religiosa de várias perspetivas, expressas no elevado número de objetivos, sumarizáveis no seguinte: caracterizar a religiosidade dos portugueses, compará-la com os países católicos europeus e compreender a influência dos fatores sociais e culturais na mesma. Com a mudança sociocultural em curso abre-se caminho para reconfigurações do religioso que importa analisar, tanto na perspetiva a jusante, do religioso em si, como a montante, das transformações sociais e culturais. Além disso, a comparação com países com a mesma matriz histórica e religiosa possibilita situar Portugal no contexto europeu.

Para implementar estes objetivos, o autor aposta na metodologia quantitativa, recorrendo ao inquérito por questionário como instrumento de trabalho. O EVS, porventura a base de dados internacional mais indicada para o estudo da religião, pela variedade e adequabilidade dos indicadores disponíveis, foi usado exaustivamente e na maioria das vezes de forma longitudinal. Desdobrando-se em dimensões, indicadores e análises, o autor disponibiliza dados e informação em abundância, numa área pouco estudada no nosso país. A tese de doutoramento de Oliveira (1995), com pontos convergentes com a de Duque, concorreu no seu tempo para aumentar o conhecimento da realidade religiosa portuguesa, pela análise do contexto social, como pela caracterização minuciosa da população portuguesa em termos religiosos. No entanto, para além da sua perspetiva sincrónica, encontra-se relativamente desatualizada. Resumidamente, o contributo valioso de 
Duque com este livro, para além da atualidade, da diacronia e da comparação internacional, passa pela caracterização extensiva da religiosidade (desenvolvendo índices, analisando dimensões e cruzando variáveis) e pelo estudo da relação dos fatores socioculturais com a religiosidade.

Passemos agora a olhar para cada capítulo. Após justificar a pertinência do seu estudo no capítulo primeiro (introdução), o autor faz o enquadramento teórico no capítulo segundo. Começa pela definição de religião, cuja dificuldade, que o autor menciona e discute, se coloca habitualmente nos estudos desta área. Seguindo Berger, Duque considera que a definição tem de ser construída em função de determinada pesquisa, pois a validade universal das definições torna-se impossível devido à enorme variedade de objetos religiosos. A sua definição parece oportuna, tanto pelos autores escolhidos (por exemplo, Durkheim ou Luckmann), como pelo ajustamento à realidade estudada. De seguida, o autor desenvolve a sua narrativa sobre a evolução da razão na modernidade, na secularização e no desencantamento do mundo como sua consequência, o que demonstra bem a influência de Weber. Como refere Duque, não estando consumada a modernidade, na pós-modernidade tudo se torna possível, nomeadamente o retorno do religioso, porventura renovado e consolidado, mas agora marcado pela subjetividade, pela abertura e pela contingência. Talvez a "arte" pudesse ser mais explorada. Sobre a secularização, os trabalhos de síntese de Dobbelaere ou Tschannen, os contributos de Bruce, Davie ou Taylor poderiam ser lembrados; Martin e Casanova poderiam ser referidos não só em notas de rodapé, mas no corpo do texto. Autores como Hervieu-Léger, Heelas ou Woodhead poderiam ser bastante úteis para melhor definir a religiosidade pós-moderna, indo ao encontro do pretendido por Duque. As recomposições religiosas, a religião à la carte, a bricolage são assuntos centrais em Hervieu-Léger, enquanto a dicotomia religião/espiritualidade é discutida por Heelas e Woodhead. Para terminar o enquadramento teórico Duque desenvolve e explora as três teorias que subjazem à mudança sociocultural atual e que são testadas diretamente neste trabalho (individualização, materialismo /pós-materialismo e centro/periferia); daí justamente o seu destaque relativamente às outras questões teóricas.

No capítulo terceiro, Duque expõe a metodologia usada, quantitativa, assente em desenhos longitudinais, com dados de 1990, 2000 e/ou 2008, tendo em vista entender as tendências ao longo do tempo. Relativamente às fontes, $\mathrm{o}$ autor baseia o seu estudo no EVS, apoiando-se ainda, a nível internacional, nas bases de dados do Vaticano e, a nível nacional, no INE e nos dados fornecidos pela igreja, o que parece a melhor opção. Termina descrevendo os indicadores e as análises usadas (univariadas, bivariadas e multivariadas), as quais são muitas e variadas, o que demonstra o empenho do autor na qualidade da sua obra.

No capítulo quarto, passa-se para a análise dos resultados da dimensão religiosa, com quatro partes. Na primeira parte, na autoidentificação religiosa, enquadram-se os seguintes indicadores: sentimento religioso, pertença religiosa e matriz religiosa dominante. Refira-se, todavia, que, devido à subjetividade inerente à interpretação dos mesmos, a sua utilização requer cuidado. Na segunda parte, na assistência aos serviços religiosos, relembre-se que este é o indicador mais antigo da religiosidade e, apesar das suas limitações, talvez seja dos mais fiáveis. Basta 
lembrar que os censos da igreja e os vários estudos portugueses realizados neste domínio, tal como o estudo mais recente de Teixeira (2013), sempre se apoiaram neste indicador. A terceira parte começa pela dimensão religiosa (importância de Deus, importância da religião, consolo e fortaleza na religião). No final desta análise o autor apresenta um índice de religiosidade baseado nas seguintes variáveis: prática religiosa, frequência de oração, importância de Deus na vida, importância da religião na vida, sentimento religioso, crença em Deus, conceção de Deus. Consciente da complexidade da realidade em estudo e da inadequação de análises anteriores baseadas somente na prática religiosa, porventura mais adequadas para sociedades menos complexas, o autor desenvolve justamente este índice, assente tanto nas práticas como nas crenças e nas atitudes. Depois da dimensão religiosa passa para a dimensão valorativa (atitudes frente a diferenças sociais, aceitação de comportamentos sociais, importância da família). Com bases em indicadores desta dimensão desenvolve uma análise de componentes principais, para reduzir a informação existente, chegando a três fatores: consciência moral, tolerância e dimensão relacional. Passa de seguida para a dimensão crencial (Deus, vida depois da morte, inferno, céu, pecado e reencarnação; e conceito de sobrenatural). Com todas as variáveis, exceto a última, o autor cria um índice de crencialidade. Por fim, Duque apresenta a dimensão institucional (atitudes perante a igreja - confiança nas instituições, pertença a organizações e atividades de voluntariado; resposta institucional - ritos e sacramentos, outras respostas da igreja aos problemas morais, problemas da vida familiar, necessidades espirituais, problemas sociais do seu país). No final do capítulo o autor analisa a desinstitucionalização religiosa, criando uma escala para medir a religiosidade privada e pública com indicadores apropriados. Na primeira usa os indicadores: crença num Deus pessoal, importância de Deus, sentimento religioso, frequência à oração e se encontra consolo e fortaleza na religião. Na segunda usa os indicadores: prática religiosa, grau de confiança na igreja, importância dada aos três ritos de passagem. Por último, define novas dimensões de religiosidade conjugando três indicadores (sentimento religioso - religiosidade privada, prática religiosa - religiosidade pública, e posição religiosa - religiosidade privada e pública).

No capítulo quinto passa para a análise da dimensão sociocultural, estudando a individualização, o materialismo/pós-materialismo e a posição social. Na individualização, após aplicação de análise fatorial verificam-se as variáveis que melhor explicam os valores tradicionais e de individualização, respetivamente. Com base na polarização dos dois valores mais importantes de cada, constrói um índice, analisando-o de seguida. No segundo aspeto, usam-se quatro indicadores apropriados para se construirem escalas e assim determinar os materialistas, os pós-materialistas e os mistos. Para se analisar a posição social, constrói-se um índice com base em sete variáveis sociodemográficas. Por fim, o autor faz a correlação entre a segunda dimensão e as duas outras, para testar as hipóteses: quanto maiores o grau de individualização e a posição social maiores os valores pós-materialistas.

No capítulo sexto procede-se ao estudo da relação entre as dimensões religiosa e sociocultural. Cruza-se a posição religiosa e a prática religiosa com os índices/escalas acima referidos. Analisa-se a capacidade preditiva de modelos 
sociodemográficos, valorativos e socioculturais sobre a religiosidade. Por último, analisa-se a predição das variáveis dos modelos sobre a religiosidade. Depois de se concluir que são as variáveis do modelo sociocultural que predizem mais a religiosidade, segue-se para a sua análise.

No capítulo sétimo, discutem-se os resultados e apresentam-se as conclusões. Na discussão aborda-se a confirmação das três hipóteses do livro. A primeira hipótese não é rejeitada, ou seja, à medida que as sociedades se desenvolvem reestrutura-se a dimensão valorativa, o que reconfigura uma nova mentalidade. A segunda hipótese também não é rejeitada, ou seja, a reconfiguração da mentalidade leva à criação de novas formas de religiosidade de foro mais privado e desinstitucionalizado. A terceira hipótese não é igualmente rejeitada, ou seja, embora Portugal partilhe muitos valores com os outros países, ao contrário deles, a religião tem ainda forte expressividade. Na conclusão, Duque sintetiza primeiro os principais resultados do estudo, o que parece acertado em vista do acervo produzido. Por fim, apresenta as principais conclusões do estudo, que se resumem no seguinte: "Fica, assim, claro, que se assiste a uma reconfiguração da religiosidade portuguesa motivada, em parte, pelos valores emergentes, o que demonstra que esta religiosidade não é alheia às mudanças socioculturais, próprias do desenvolvimento da sociedade, mas sim, que se metamorfoseia, adaptando-se às particularidades que definem a mentalidade contemporânea."

\section{Referências bibliográficas}

Duque, Eduardo (2008), El Fenomeno Religioso y Sus Influencias Sociales. Perfiles y Tendencias del Cambio Religioso en Portugal, Madrid, Universidade Complutense de Madrid, tese de doutoramento em Sociologia.

Oliveira, Carlos (1995), Atitudes e Comportamentos Religiosos dos Portugueses na Actualidade, Évora, Universidade de Évora, tese de doutoramento em Sociologia.

Teixeira, Alfredo (2013), “A eclesiosfera católica: pertença diferenciada”, Didaskalia, XLIII (1/2), pp. 115-205.

José Pereira Coutinho (corresponding author). Investigador, Númena. Taguspark Núcleo central, 379, 2740-122, Porto Salvo. E-mail: jose.coutinho@numena.org.pt 